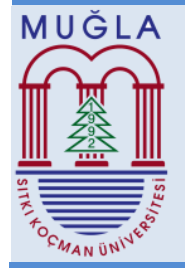

\title{
A WIRELESS SENSOR NETWORK APPLICATION FOR VEHICLE TRACKING IN CAMPUS AREAS
}

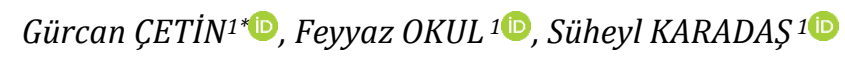 \\ 1Department of Information Systems Engineering, Faculty of Technology, Muğla Sitkı Koçman University, 48000, Muğla, Turkey \\ gcetin@mu.edu.tr, feyyazokul@posta.mu.edu.tr , suheyl@mu.edu.tr
}

Received: 22.10.2017, Accepted: 07.12.2017

*Corresponding author

doi: $10.22531 /$ muglajsci.357087

\section{Abstract}

In this study, a Wireless Sensor Network structure was designed in order to track the vehicles entering a certain safe zone in real time, and it was tested in the campus area of Muğla Sitkı Koçman University. To track the locations of the vehicles in the designed WSN infrastructure, a GTPAO10 GPS module was used at the end devices components placed on vehicles. Moreover, the XBee S1 modules based on the ZigBee protocol were used to wirelessly transmit the obtained location data to a center node. An ASP.Net-based web application has been developed to graphically present the vehicle location information in a security center and record them in the MSSQL database at intervals of 5 minutes. It also notifies system administrators in case of long waiting times of the vehicles in the areas outside the pre-specified areas. At the end of the study, it has been proved that WSNs can be used as alternatives to wireless network infrastructures such as GSM or WIFI when vehicles are tracked in small scale campus areas.

Keywords: Vehicle tracking, GPS, XBee, ZigBee

\section{YERLEŞKE ALANLARINDA ARAÇ TAKİBİ İÇİN BİR KABLOSUZ ALGILAYICI AĞ UYGULAMASI}

$\ddot{\mathbf{O z}}$

Bu çalışmada belirli bir güvenli bölgeye giren araçları gerçek zamanlı olarak takip etmek amacıyla bir Kablosuz Algılayıcı Ağ tasarlanmış ve Muğla Sitkı Koçman Üniversitesi yerleşke alanında test edilmiștir. Tasarlanan ağ yapısında araçlara yerleştirilen düğüm noktalarında konum takibi için GTPA010 GPS modülü, algllanan konum bilgisinin istenilen noktaya kablosuz olarak iletilmesinde ZigBee protokolüne dayanan XBee S1 modülleri kullanılmıștır. Uç düğümlerden alınan araç konum bilgilerinin güvenlik merkezi olarak kullanılacak bir merkezde grafiksel olarak sunulması ve 5 dakikalık aralıklar ile MSSQL veri tabanında kayıt edilmesi için ASP.Net tabanlı bir web uygulaması geliştirilmiştir. Ayrıca, uygulama ile yerleşkeye giren araçların belirlenen alanların dıșında uzun süreli beklemeleri durumlarında sistem uyarı vererek bilgi vermektedir. Calıșma sonunda, küçük ölçekli yerleş̧ke alanlarında araçların takip edilmesinde KAA'ların, GSM ya da WIFI gibi kablosuz ağ altyapılarına alternatif olarak kullanılabileceği kanitlanmiștır.

Anahtar Kelimeler: Araç takip sistemi, GPS, XBee, ZigBee

\section{Introduction}

WSN (Wireless Sensor Network) is a wireless data transmission system consisting of many inexpensive sensor nodes which are densely deployed either inside the phenomenon or very close to it. The application areas of WSNs have become widespread in recent years, thanks to the innovations in micro electro-mechanical systems (MEMS), wireless communications, digital electronics and sensors having low-power, low-cost and small in size [1]. WSNs increase the efficiency of a system by allowing the collaboration of many sensor nodes. Thus, WSNs have found an important place in areas such as data acquisition systems [2], environmental monitoring [3], automated control mechanisms [4], agriculture [5], wearable healthcare applications [6], office and home automation systems [7, 8].

In this work, with the advantages provided by WSNs, we have developed a vehicle tracking system which can be used to monitor the position data of vehicles in real-time or past. Considering the studies done in recent years, vehicle tracking systems on WSNs have been successfully applied to design a smart vehicle [9], detect of a vehicle position by utilizing signal values [10] or based on GPS (Global Positioning System) $[11,12]$.
The main purpose of tracking the vehicle positions in the campus area is to ensure the security of the campus, and to notify the system administrator in case of long waiting times of the vehicles in the areas outside the pre-specified areas. Parking the vehicles at undesired places within the campus can cause problems in emergencies. It may also be necessary to security investigation about when a vehicle has visited the campus or where it positioned within the campus area.

To track the locations of the vehicles in the designed WSN infrastructure, a GTPA010 GPS module was used at the end devices components placed on vehicles. Moreover, the XBee S1 modules based on the ZigBee protocol were preferred to wirelessly transmit the obtained location data to a center node.

The ZigBee protocol is a D2D (Device-to-Device) communication protocol that provides data communication with multiple intermediate nodes (multihop) transmission instead of using the Internet infrastructure. The main reason for using the ZigBee protocol in this work is that the ZigBee protocol allows the complex WSN fields to be established and that these fields can then be expanded to meet the needs or communicated with other networks [13]. 
In the study, we have also developed an ASP.Net-based web application to graphically present the vehicle location information in a security center and record them in the MSSQL database at intervals of 5 minutes. The developed web interface allows the authorized users to monitor real-time vehicle location data. Furthermore, vehicle location history can be traced later on this platform. We successfully tested our developed vehicle tracking system on WSN in the campus of Muğla Sıtkı Koçman University.

The remainder of the article is organized as follows; In Chapter II, WSNs and the ZigBee protocol are addressed. The software and hardware architecture issues of the designed vehicle tracking system are explained in detail in Chapter III, and the results of working are given in Chapter IV.

\section{Wireless Sensor Networks}

WSN is a wireless data transmission system consisting of many inexpensive sensor nodes which are densely deployed either inside the phenomenon or very close to it. Moreover, in a WSN, sensor nodes can be capable of collecting, storing and processing of environmental data. One of the unique features of Wireless Sensor Networks is the collaborative efforts of sensor nodes [1]. WSN systems are autonomous and operate unattended, adaptive to the environment. Thus, in the WSNs, a larger sensing task can be divided into small tasks, in which a group of sensors coordinated among themselves can be distributed. Randomly distributed small sensor nodes in a WSN field are shown in Figure 1. The sensor nodes transmit the obtained data to the sink nodes in the multi-hop connections. And finally, collected all data of the WSN environment are transferred to the long-distance centers [8].

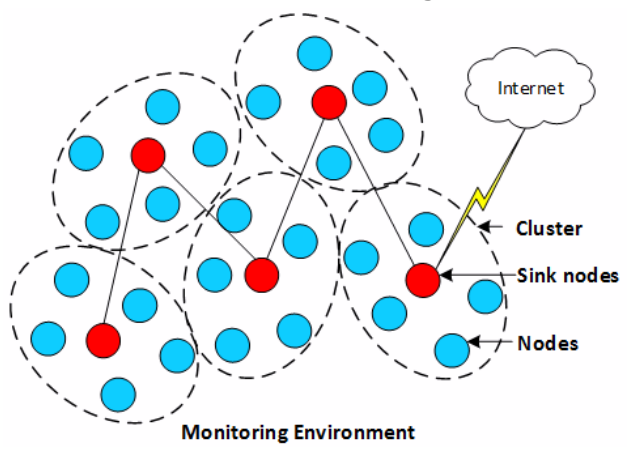

Figure-1: Architecture of WSN systems

Although many algorithms and protocols are offered for traditional wireless ad-hoc networks, they cannot provide the application requirements of WSNs as well. The main reason for this; the number of sensor nodes in the WSN is several times greater than the nodes in the ad-hoc networks, depending on the application, and the network topology of the sensor nodes changes frequently in a WSN area [15].

Many WSN platforms have been developed such as MICA2, MICAz, TelosB, MOTE, Dust Network and XBee. However, standards are needed to ensure interoperability of different systems. The ZigBee was emerged for this purpose [16].

\section{$2.1 \quad$ ZigBee}

The ZigBee networking stack is built on the IEEE 802.15.4 standard. It is widely studied and preferred to build WPAN (Wireless Personal Area Network) areas due to its low cost, low power consumption, low data rate, simplicity and flexible construction. In the ZigBee technology, IEEE is responsible for development of physical layer (PHY), media access control layer (MAC) and data link layer as shown in Figure 2. On the other hand, data transmission encryptions, determining logic networks, application interface specifications and communication specifications between system products are the responsibility of ZigBee Alliance [2].

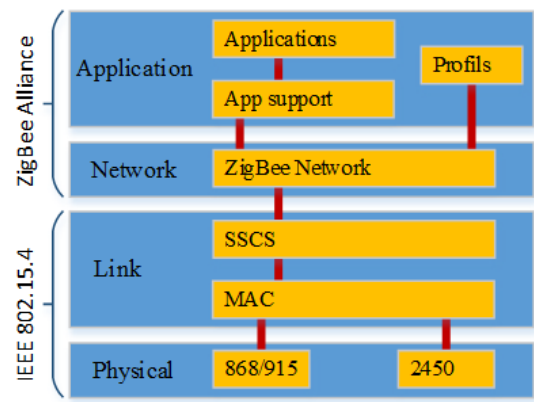

Figure-2: ZigBee protocol stack

Figure 3 shows the comparison of the ZigBee protocol with other wireless protocols (Bluetooth, IEEE 802.11 and IEEE 802.15.3) in terms of two key performance characteristics: wireless radio range and data transmission speed. ZigBee has the ability to work in a wide range of communications and low rate transmission [8].

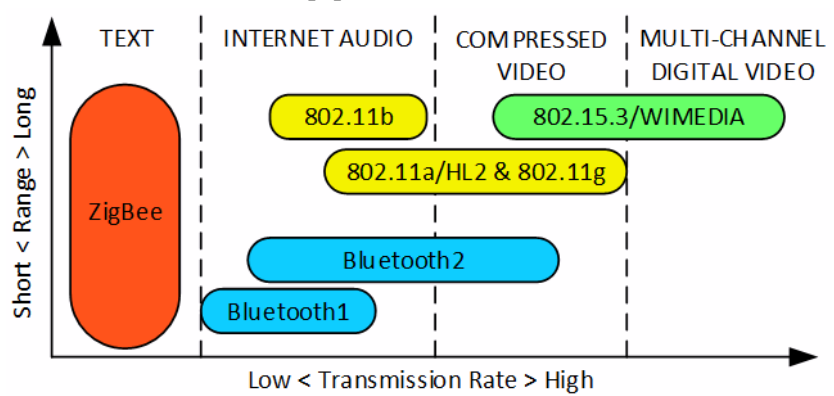

Figure-3: The wireless landscape

ZigBee protocols supports different network topologies such as tree, star and mesh as shown in Figure 4. The Star Topology employs Multipoint-to-Point connectivity between nodes. There is a single hop for all connections, which are Point-to-Point. On the other hand, mesh topology has multiple data paths and multi-hops. Thus mesh WSN networks have self-configuring and self-healing protocols [8].

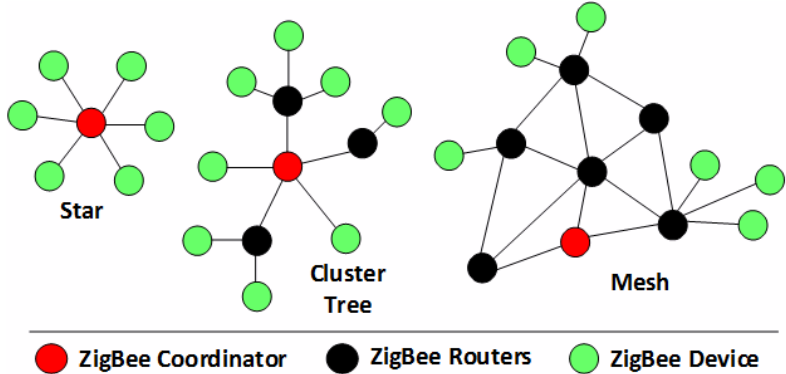

Figure-4: ZigBee topologies

\section{Designed Vehicle Tracking System}

We integrated different software and hardware components to work together during the design of a real-time vehicle tracking system. The infrastructure of the system developed in the study is divided into two main divisions; hardware architecture and software components.

Figure 5 illustrate the main structure of the designed system. The position information received by the GPS module is transferred to the coordinator XBee module via XBee Series 1 end nodes. The WSN structure was configured in a star topology between the end XBee devices and the coordinator XBee module. A USB - UART converter is used for data communication between the coordinator XBee module that 
acts as a gateway and the computer. Finally, the data collected from different end XBee modules are presented graphically on the internet to authorized users via web application developed in ASP.Net environment, and it stored in MSSQL database every 5 minutes for future usage.

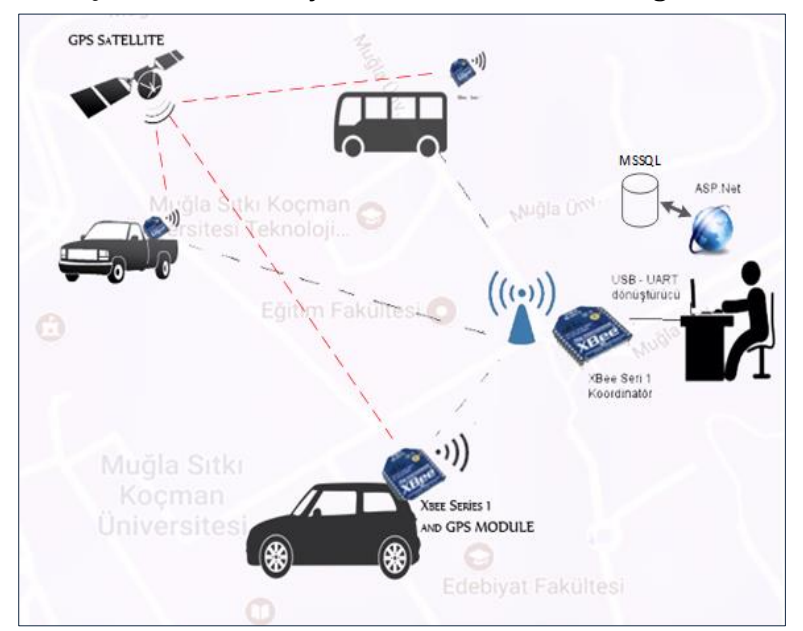

Figure-5: Designed vehicle tracking system

\subsection{Hardware Architecture}

WSNs can also work interactively with GPS modules in addition to simple sensors. The electronic circuit structure of the sensor nodes of the designed system is given in Figure 6. The sensor circuit is placed in the vehicles to be monitored, and the GPS module obtains the vehicle position information. Then, it transmits the XBee module to the Tx/Rx ports with 9600 baud rates.

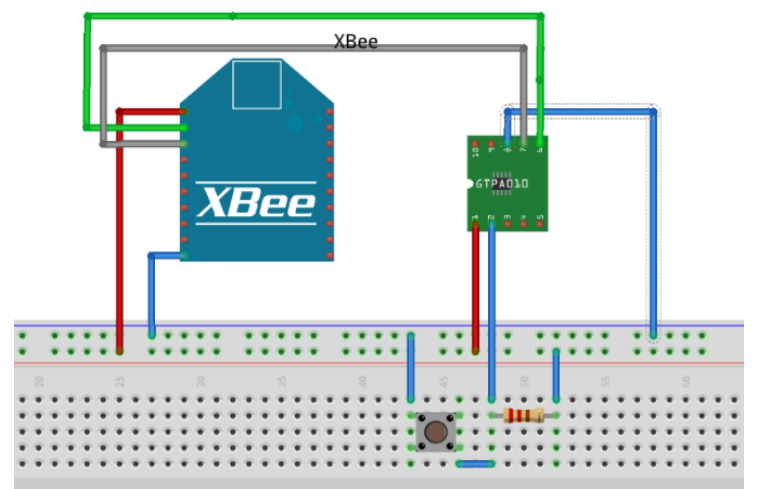

Figure-6: Electronic circuit of sensor nodes

\subsubsection{XBee}

We selected the XBee S1 as a radio frequency (RF) module in this work because of its ease of implementation and reliability in the process. The XBee modules are configured using the XCTU platform as shown in Figure 7 at a 9600 baud rate.
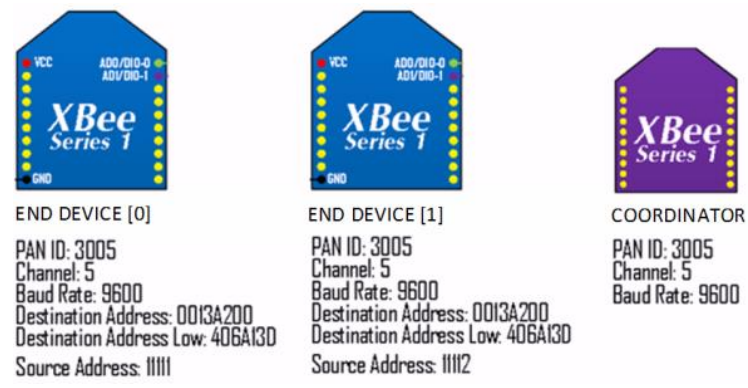

COORDINATOR

PAN ID: 3005

Baud Rate: 9600

Source Address IIIII

Figure-7: XBee Configuration Parameters in Star Topology

The XBee is a $2.4 \mathrm{GHz}$ radio module that transmits sensor data from each node to the gateway. Covered area of the XBee $\mathrm{S} 1$ module is between $30 \mathrm{~m}$ (indoor) and $120 \mathrm{~m}$ (outdoor). It consumes $50 \mathrm{~mA}$ of power in receive mode and $45 \mathrm{~mA}$ in transmission mode. This consumption falls below $10 \mu \mathrm{A}$ in sleep. A $15 \mathrm{~ms}$ time is required to exit the sleep state [17].

\subsubsection{GPS Module}

The GPS (Global Positioning System) is a space-based radio navigation system that transmits regularly encoded information by using 24 satellites. It provides geolocation and time information to a GPS sensors. GPS sensors calculate the position using an algorithm based on the signal received from the satellite. When the GPS module receives signals from at least four different satellites, it can calculate the position on earth. Moreover, the higher the number of satellites, the greater the accuracy. The correctness of the GPS data varies between 1 and $100 \mathrm{~m}$, depending on the speed of the sensor and the environmental conditions [12]. In this work, we used the GTPA010 GPS module, shown in Figure 8, at the end nodes for keeping track of location of the vehicles.

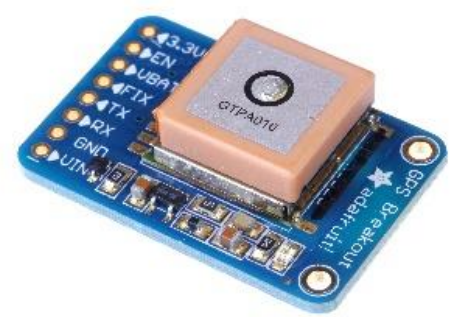

Figure 8: GTPA010 GPS Module

GTPA010 GPS module is a standalone GPS receiver with inbuilt antenna. It is built around MTK3329 GPS chipset. Furthermore it has a low power consumption: $55 \mathrm{~mA}$ in acquisition, $40 \mathrm{~mA}$ in tracking.

\subsection{Software}

In the designed vehicle tracking system, ASP.Net based web application has been developed so that all the data collected by WSN can be graphically presented to the system administrators in real time over the internet. Figure 9 shows that the location information from the sensor nodes which are placed on vehicles entering the Muğla Sitkı Koçman University campus area is presented to the user in a single screen interface. The vehicles in the correct locations and the vehicles in the wrong locations are shown with different icons on the map. Besides this, it notifies system administrators in case of long waiting times of the vehicles in the areas outside the pre-specified areas. 


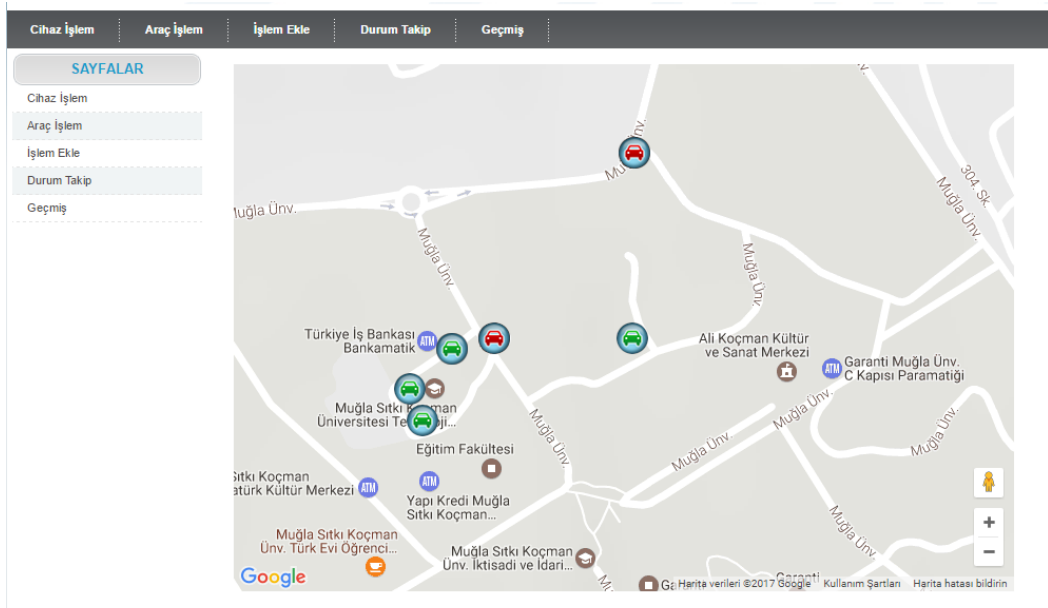

Figure-9: Development software for tracking vehicle system

The software uses the Google APIs for the map. Google Maps API is a web mapping service established by Google that allows maps to be embedded on third-party websites. The JavaScript programming language is also used to mark the locations of the vehicles on the map. Map options for MSKU are given below.

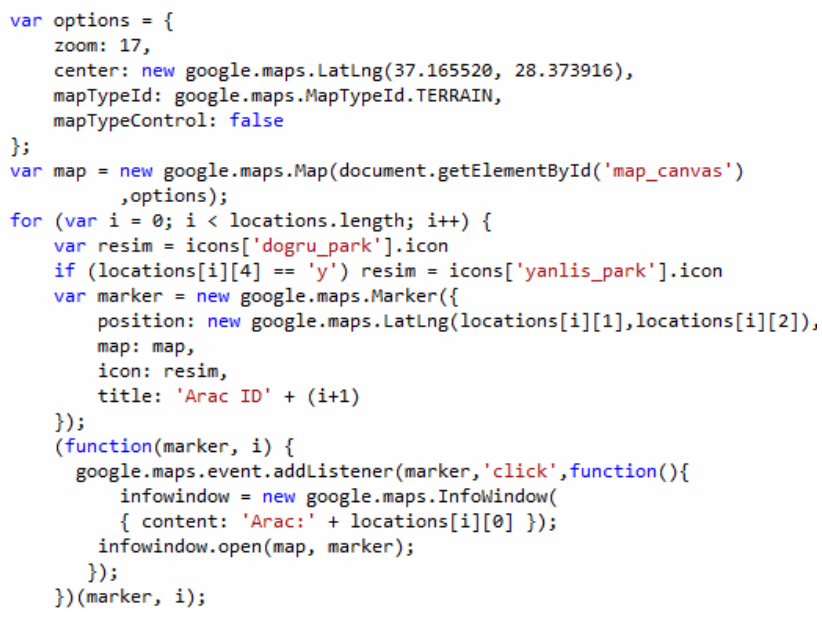

In the enhanced vehicle tracking platform, it is sufficient to click on the vehicle icon shown in Figure 10 to query the vehicles. Thus, vehicle plate numbers and the ID numbers of the sensors on the vehicles can be learned.

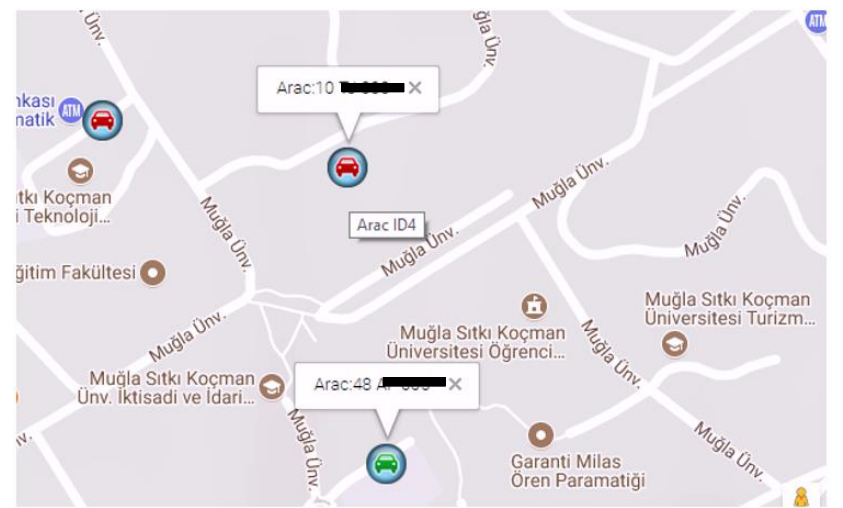

Figure 10: Querying of the tracked vehicles

With the developed software, the vehicle location information from the end nodes can also be recorded in the MSSQL database at intervals of 5 minutes to query the locations of a
In the software, the pages in Figure 11 and Figure 12 are used respectively for the processes for adding the vehicle to the system, receiving the sensor devices from the vehicle and assigning the device to the vehicle.

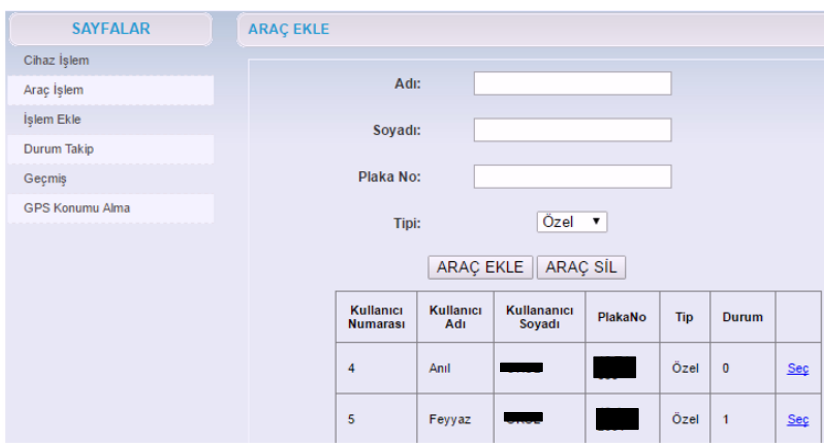

Figure 11: The page of vehicle adding and vehicle delete

\begin{tabular}{|c|c|c|c|c|c|c|c|}
\hline Cihaz iglem & Araç ig̣lem & igslem Ekle & Durum Takip & & Geģmiş & \multicolumn{2}{|c|}{ GPS Konumu Alme } \\
\hline \multicolumn{2}{|c|}{ SAYFALAR } & CIHAZ EKLE & & & & & \\
\hline \multicolumn{8}{|l|}{ Cihaz İșlem } \\
\hline \multicolumn{2}{|l|}{ Araç İșlem } & & Cihaz Adl: & & & & \\
\hline \multicolumn{2}{|l|}{ Ișlem Ekle } & & \multirow{2}{*}{\multicolumn{2}{|c|}{ CIHAZ EKLE }} & $\mathrm{CH}$ & & \\
\hline \multicolumn{2}{|l|}{ Durum Takip } & & & & \multirow{2}{*}{\multicolumn{2}{|c|}{ Kullanım Durumu }} & \\
\hline \multicolumn{2}{|l|}{ Geçmiş } & & Kayt No & Cihaz Ad! & & & \\
\hline \multirow{2}{*}{\multicolumn{2}{|c|}{ GPS Konumu Alma }} & & & & & & \\
\hline & & & 3 & cihaz3 & 1 & & $\sec$ \\
\hline
\end{tabular}

Figure -12: The page of assigning the device to the vehicle

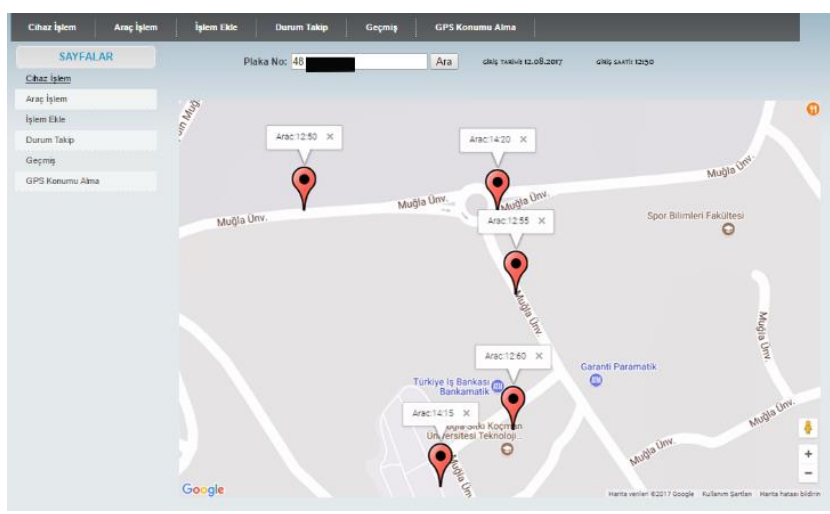

Figure -13: The page vehicle track history

vehicle in the past. The pages of vehicle track history shown in Figure 13. And, relational database in MSSQL shown in Figure 14. 


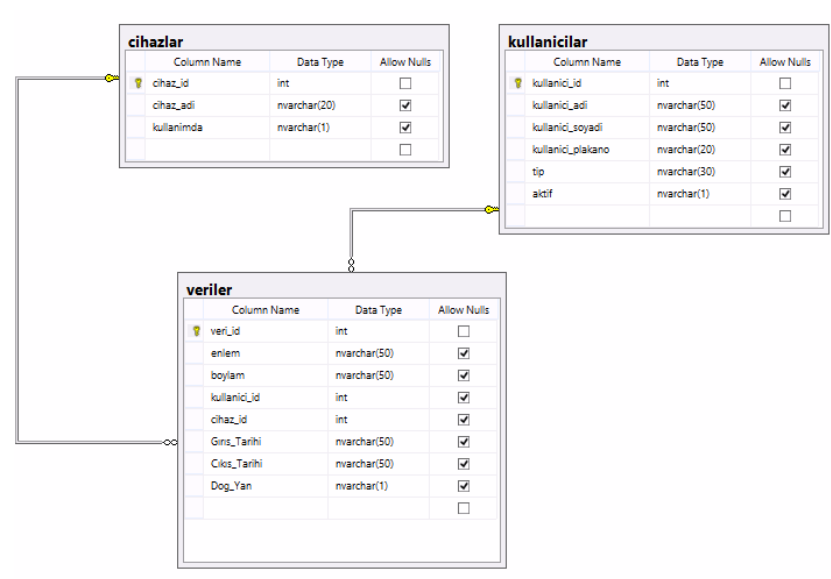

Figure - 14: Relational database of the system

\section{Conclusion}

In this study, it is achieved a design of a vehicle tracking system by using XBee modules in a WSN area. We have successfully tested the tracking system in the Muğla Sitkı Koçman University campus and the location data received by the GPS module is graphically presented to authorized users on a web platform. It has been proved that WSNs can be used as alternatives to wireless network infrastructures such as GSM or WIFI when vehicles are tracked in small scale campus areas.

It is possible to increase the functionality and coverage of the developed system, if the system uses XBee router devices and the network is designed according to the mesh topology.

\section{References}

[1]. Akyildiz, I. F. and Vuran, M. C., "Wireless Sensor Networks" Wiley, 2010.

[2]. Shariff, F., Rahim, N. A. and Ping, H. W., "Zigbee-based daha acquisition system for online monitoring of gridconnected photovoltaic system" Expert Systems with Applications, no. 42, pp. 1730-1742, 2015.

[3]. Çetin, G. Karadaş, S. Özdemir, M. Ş. and Yılmaz, Y. "IEEE 802.15.4 / ZigBee based wireless sensor network design for monitoring server rooms" International Conference on Computer Science and Engineering, 2017.

[4]. Barankova, I., Mikhailova, U. and Lukianov, G. "Automated Control System of a Factory Railway Transport Based on ZigBee" 2nd International Conference on Industrial Engineering, Applications and Manufacturing, 2016.

[5]. Rodiriquez, R. Y., Julcapoma, M. R. and Jacinto, R. A., "Network Monitoring Environmental Quality in Agriculture and Pisciculture with Low Power Sensor Nodes Based On ZigBee and GPRS Technology" XXIII International Congress on Electronics, Electrical Engineering and Computing, 2016.

[6]. Lee, C. C., Shen, Y., Lee, W. C., Hung, F. H. and Tsang, K. F., "ZigBee LNA Design for Wearable Healthcare Application" 14th International Conference on Industrial Informatics, 2016.

[7]. Huang, P. C., "ZigBee Wireless Network Application Research Case Study within Taiwan University Campus" Proceeding of the 8th IC on Machine Learning and Cybernetics, 2009.

[8]. Lin, S., Liu, J. and Fang, Y. "Zigbee based wireless sensor networks and its applications in industrial" IEEE International Conference on Automation and Logistics, 2007.
[9]. Srinivasan, R., Sharmili, A., Saravanan, S. and Jayaprakash, D., "Smart Vehicles with Everything", 2nd International Conference on Contemporary Computing and Informatics, 2016.

[10]. Fanheng Press, "The design of the vehicle location system based on wireless sensor network" International Industrial Informatics and Computer Engineering Conference, 2015.

[11]. Zeng, B. and Yao, L., "Study of Vehicle Monitoring Application With Wireless Sensor Networks" 11th International Conference on Wireless Communications, Networking and Mobile Computing, 2015.

[12]. Dener, M., "Mobile and Web Architectures of Vehicle Tracking and Human-Object Tracking Systems in Wireless Sensor Networks" Journal of Advances in Computer Networks, vol 4, no. 3, pp. 156-160, 2016.

[13]. Masica, K., "Recommended Practices Guide For Securing ZigBee Wireless Networks in Process Control System Environmets", Lawrence Livermore National Laboratory, 2007.

[14]. Akyildiz, I. F., Su, W., Sankarasubramaniam, Y. and Cayirci, E. "A Survey on Sensor Networks" IEEE Communications Magazine, vol 40, no. 8, pp. 102-114, 2002.

[15]. Pan, M. S. and Tseng, Y. C., "ZigBee Wireless Sensor Networks and Their Applications" National Chiao Tung University, Hsin-Chu, pp. 1-20, 2006.

[16]. SparkFun Electronics, [Online]. Available: https:// www.sparkfun.com/pages/xbeeguide [Accessed: 12.9.2017]. 